\title{
Functional MRI Localization of Language in a 9-Year-Old Child
}

\author{
R.R. Benson, W.J. Logan, G.R. Cosgrove, A.J. Cole, H. Jiang, L.L. LeSueur, \\ B.R. Buchbinder, B.R. Rosen and V.S. Caviness, Jr.
}

\begin{abstract}
Background: Localizing critical brain functions such as language in children is difficult and generally requires invasive techniques. Recently sensory, motor and language functions in adults have been mapped to specific brain locations using functional imaging techniques. Of these techniques, functional MRI (fMRI) is the least invasive and has the highest spatial and temporal resolution. Its use in adults is well documented but application to children has not been as well described. In the present study lateralization and localization of language was evaluated with fMRI prior to epilepsy surgery in a nine-year-old male with complex partial seizures, attentional difficulty and decreased verbal proficiency. Methods: Two language paradigms well studied in adults (read, verb generation) and two additional language paradigms (antonym generation, letter fluency) were studied using whole brain fMRI after stimulus items and timing were adjusted to achieve the desired performance level during imaging. The patient was also conditioned to the magnet environment prior to imaging. Results: Word reading and letter fluency tasks produced lateralized and localized activation similar to that seen in adults. The patient had no language deficits following an anterior $2 / 3$ dominant temporal lobe resection. Conclusions: With modifications of protocols such as those detailed in this report, this non-invasive method for localizing language function is feasible for the presurgical evaluation of children as well being applicable for a variety of developmental language issues.
\end{abstract}

\begin{abstract}
RÉSUMÉ: Localisation fonctionnelle du langage par RMN chez un enfant de 9 ans. Introduction: Il est difficile de localiser des fonctions critiques du cerveau comme le langage chez les enfants et une telle tâche requiert généralement des techniques invasives. Dernièrement, on a localisé a certaines régions spécifiques du cerveau des fonctions sensorielles, motrices et linguistiques chez des adultes au moyen de techniques d'imagerie fonctionnelle. Parmi ces techniques, la RMN fonctionnelle (RMNf) est la moins invasive et possède la meilleure résolution spatiale et temporale. Son utilisation chez les adultes est bien documentée, mais son application chez les enfants n'a pas été bien décrite. Dans cette étude, la latéralisation et la localisation du langage ont été évaluées par RMNf avant une chirurgie pour épilepsie chez un enfant de neuf ans qui avait des crises partielles complexes, des difficultés d'attention et une habileté verbale limitée. Méthodes: Deux paradigmes du langage qui ont été bien étudiés chez les adultes (la lecture, la génération des verbes) et deux paradigmes additionnels du langage (la génération des antonymes, la maîtrise des lettres) ont été étudiés au moyen de la RMNf du cerveau entier après avoir ajusté les items servant au stimulus et le chronométrage pour obtenir le niveau de performance désiré pendant l'imagerie. Le patient avait aussi été conditionné à l'environnement avant l'imagerie. Résultats: Les tâches impliquant lecture de mots et la maîtrise des lettres ont produit une activation latéralisée et localisée semblable à celle observée chez les adultes. Le patient n'avait pas de déficit du langage suite à une résection des deux tiers antérieurs du lobe temporal dominant. Conclusions: Avec des modifications du protocole comme celles qui sont décrites dans cet article, cette méthode non invasive pour localiser la fonction linguistique est utilisable pour !'evaluation préopératoire des enfants ainsi que pour certaines questions relatives au développement du langage.
\end{abstract}

Can. J. Neurol. Sci. 1996; 23: 213-219

Localization of language and other cortical brain functions is of critical importance in many neurosurgical procedures. Language lateralization is usually determined by intracarotid injection of amobarbital (Wada test), but this test is invasive and is not localizing within a hemisphere. ${ }^{1}$ Electrical stimulation of the cortex, either intraoperatively under local anesthesia or extraoperatively with implanted subdural electrodes, has certain limitations and risks, especially in children. Activation positron emission tomography (PET) can delineate distinct regions of increased blood flow associated with language function and has been used to determine cerebral dominance for language prior to epilepsy surgery in adults. ${ }^{2}$ Functional magnetic resonance imaging (fMRI) can also detect focal hemodynamic changes associated with specific brain activity. ${ }^{3}$ Language has been

From the Division of Neurology. The Hospital for Sick Children, University of Toronto, Toronto (WJL); the Department of Neurology (RRB, WJL, AJC. LLL. VSC). the Department of Neurosurgery (GRC. HJ), Massachusetts General Hospital, Boston; and MGH-NMR Center, Department of Radiology, Massachusetts General Hospital.

Charlestown (RRB, WJL, BRB, BRR).

RECEIVED $\propto$ TTOBER 25, 1995. ACCEPTED IN FINAL FORM MARCH 26, 1996.

Reprint requests to: Dr. Randall Benson, Massachusetts General Hospital, Harvard Medical School, Bldg. 149, 13th Street. Charlestown. MA USA 02129-2060 
successfully lateralized ${ }^{4-6}$ and localized ${ }^{7-9}$ with $\mathrm{fMRI}$ in adult volunteers and neurosurgical patients prior to surgery.

In children, the Wada test has been used to determine language lateralization, but it has several limitations in addition to the requirement for intra-arterial catheterization. 2,10.11 PET is less invasive but does require administration of a radioactive substance. fMRI, which is not invasive, is potentially more useful in children. In this younger age group, however, several questions remain to be answered. First, will children tolerate the environment of the fMRI including scanner noise, physical confinement and need to remain motionless? Second, will the immature brain have activation-related hemodynamic changes similar to the adult? Finally, will the same paradigms used for lateralizing and localizing language in adults be effective in children, or will modifications of these or different paradigms be required? Preliminary reports suggest that fMRI is possible in children ${ }^{12,13}$ and that it may be useful in lateralizing language. ${ }^{14-16}$ The present report describes the techniques used and the results obtained in the successful fMRI localization of language activation in a child with epilepsy. ${ }^{17}$

\section{CASE REPORT}

A nine-year-old right-handed male with intractable epilepsy was seen for presurgical evaluation. He had complex partial seizures with onset at age four years which were now uncontrolled with anticonvulsant therapy.

He was the product of a full-term normal pregnancy but precipitous delivery. He was said to be cyanotic at birth and spent several days in a neonatal intensive care unit. His early development was within normal limits. He began to speak phrases at two years. He attended fourth grade but required special classes because of learning difficulty. There was no family history of epilepsy but an older brother was thought to have attention deficit disorder.

The general physical examination was normal. Neurological examination demonstrated some difficulty with addition and spelling, but no abnormalities of cranial nerve, motor, gait, coordination, sensory or reflex function. Neuropsychological evaluation revealed a full scale IQ of 82, a verbal IQ of 73 and a performance IQ of 95 . Receptive vocabulary for the Peabody Picture Vocabulary Test-Revised, a measure correlating highly with verbal $I Q$, fell in the impaired range at the age equivalence of 6.4 years. He had particular difficulty with vocabulary, verbal abstraction, object naming, reading comprehension and fund of knowledge while oral reading was better at the 37 th percentile. Attention deficit disorder was suggested by clinical observation and by his performance on visual span repetition and organization of complex visual information. A handedness questionnaire (Edinburgh assessment) revealed strong right handedness.

An EEG revealed a left midtemporal epileptic focus. Video EEG recording captured his ictal events which correlated with bursts of rhythmic $8-9 \mathrm{~Hz}$ activity maximal at $\mathrm{T} 3$ and $\mathrm{Tl}$ followed by postictal slowing over the left temporal region. An MRI showed a decrease in volume of the left temporal lobe and diminished gray-white matter delineation . An ${ }^{18}$ F-fluoro-deoxyglucose PET scan revealed marked hypometabolism of the left temporal region. A functional MRI evaluation of language was performed (see Results).

The patient underwent a left anterior temporal lobectomy under general anaesthesia without complication. Pathological examination of the excised tissue revealed focal cortical dysplasia and is reported in detail elsewhere. ${ }^{18}$ The patient has been seizure free since surgery and has no language or neurological deficits.

\section{MeThods}

\section{Language Testing}

\section{A. Modification of Language Paradigms}

Since the language localization protocol had previously been employed in adults, it was necessary to assess the patient's ability to perform these tasks (reading and verb generation). Because of the patient's known verbal deficiencies, less demanding tests of verbal fluency (letter fluency) and semantic knowledge (antonym generation) were also used. During a practice run a judgement was made as to whether the patient understood and could perform the particular task. The stimulus (letter or word ) difficulty and rate of presentation were adjusted to be somewhat challenging but to avoid frustrating the patient, i.e., the accuracy was adjusted to be $80-90 \%$. During the fMRI testing, the stimuli were presented at a rate of one every 3 seconds except for a second run of the verb generation task where the rate was one every 2 seconds.

\section{B. Visual Language Tasks}

1) Reading words - single concrete nouns were presented which the patient was instructed to read silently to himself without moving his mouth (covertly). 2) Verb generation - a concrete noun was presented and the patient instructed to think of a use for the word. (e.g. the verb throw would be appropriate for the noun ball.) 3) Antonym generation - a word was presented and the patient was instructed to think of a word that was opposite in meaning (e.g., "up" for "down"). 4) Letter fluency - a letter was presented and the patient was instructed to think of a word beginning with that letter.

\section{Patient Preparation}

On the day prior to imaging the patient was accompanied by his parents to the MRI facility. Initially the patient rehearsed the various language tasks giving his responses aloud in order to gauge performance, i.e. accuracy, reaction time, and attention to task. After the task parameters were adjusted to achieve the desired performance, additional trials were performed with the patient responding covertly until it appeared that he was comfortable with the procedure. All stimuli were presented as black letters on flash cards. It was explained that he would see similar stimuli (including many of the practice items) on a screen during imaging. Prior to imaging the patient was brought into the scanning room and placed in the scanner. The imaging procedure was explained to him including the importance of not moving during the test and he was warned about the loud scanner sounds. He was reassured that he could communicate with the operators at all times.

\section{Neuroimaging}

\section{A. Equipment}

Echo planar(EPI) and conventional images were obtained using a high-speed whole body scanner (1.5 Tesla General Electric Signa modified by Advanced NMR Systems) and a quadrature head coil. The patient's head was immobilized within the coil by packing with foam rubber pads and by using Velcro straps.

\section{B. Scanning procedure}

1) Localizer - $\mathrm{T} 1$-weighted conventional saggital spin-echo images. 2) Flow Oblique - Conventional $\mathrm{T} 1$-weighted flow-compensated oblique images in plane with functional images. 3) High resolution - EPI Tl-weighted oblique images $(1.5 \mathrm{~mm} \mathrm{x}$ $1.5 \mathrm{~mm}$ ) in plane with functional images. 4) Functional imaging - Asymmetric spin-echo sequence (TE $=75 \mathrm{~ms}, \mathrm{TR}=3 \mathrm{sec}$, offset $=-25 \mathrm{~ms})$ for $\mathrm{T}^{*}$ - weighted images signal change. 13 equally spaced oblique axial slices $(7 \mathrm{~mm}$ thickness with $1.5 \mathrm{~mm}$ 
interspace) through the brain. 1014 images acquired during each activation study ( 78 images/slice in $234 \mathrm{sec}$ ). 5) High resolution - T1-weighted volumetric SPGR (1.2 mm isotropic) images for surface rendering.

\section{Stimulus Presentation}

Visual stimuli were presented by a Maclntosh IIvx, projected (Sharp XG-2000G projector) through a collimating lens and displayed on a rear projection screen placed within the MRI scanner adjacent to the headcoil. The patient viewed the screen through a two mirror attachment on the headcoil for an effective eye to screen distance of about $30 \mathrm{~cm}$. The visual angle of the full field was 28-30 degrees and of individual letters was approximately 1.5 degrees. The paradigms consisted of alternating one minute blocks of visual fixation on a crosshair and a language task for 4 minutes (read and verb generation first repetition) beginning with fixation. In the three remaining scans (verb generation second repetition, antonymn generation, letter fluency) the block lengths were $30 \mathrm{sec}$ to allow for a greater number of transitions over the same 4 minute duration. The interstimulus interval (ISI) was $3 \mathrm{sec}$ in all runs except for verb generation second repetition where it was set at 2 sec to approach the $1.5 \mathrm{sec}$ ISI used for adults. ${ }^{4}$

\section{Data Analysis}

Patient head motion was detected and corrected using image registration software adapted for fMRI by Jiang et al, $1995^{19}$ from Woods et al, 1992. ${ }^{20}$ Non-subtractive statistical maps were generated pixel-by-pixel using the nonparametric KolmogorovSmirnov (KS) statistic, ${ }^{3.21}$ contrasting language and baseline (fixation) conditions after mildly smoothing the functional images with a Hanning filter to increase signal to noise.

\section{Image Display}

The statistical maps of the functional imaging data were superimposed on the $\mathrm{Tl}$-weighted high resolution EPI images. Maps were transformed to $-\log _{e} p$ maps, taking into account the number of time points for each condition. Voxels with suprathreshold statistical values were represented in pseudocolour. A 3-dimensional surface rendering of the brain was constructed using the software Analyze. ${ }^{22}$ Functional and anatomical images were coregistered and fused to produce a surface rendering of foci. Only cortical and immediate subcortical activity was rendered on the surface. Foci with $p$-values less than a given threshold $(0.1$ or 0.01$)$ were displayed monochromatically.

\section{Assessment of Language Lateralization}

A hemisphere activity index, $A$, was calculated for each hemisphere as the sum of all voxel $-\log _{e} p$ values (a weighted sum) for all voxels with $-\log _{e} p>0$, i.e., all voxels which are positively correlated with the language condition. ${ }^{4}$ Thus, $A$ $=\sum k_{i}$, where $k$ is the $-\log _{e} p$ value of the $i$ th voxel. The hemisphere laterality ratio (HLR) is then expressed as: $\mathrm{HLR}=A_{L} / N_{L}$ $/ A_{R} / N_{R}$. where $\mathrm{N}$ is the total number of voxels for each hemisphere: These activity and laterality indexes were described by Benson, et al. ${ }^{4}$ using data from 18 adult controls and 28 patients for the reliably lateralizing verb generation task. 10 of the 28 patients had language laterality evaluated by intracarotid amobarbital with all 10 cases concordant for the two modalities. All 10 right handed controls had a laterality ratio exceeding 1.20 with a mean $1.40 \pm 0.14$ sd. Of the 3 right dominant left handed volunteers (dominance based on hemisphere and regional laterality assessments), the highest laterality ratio was 0.88 with a mean of $0.71 \pm 0.15$. Similarly, the less reliably lateralizing reading words task had a mean of $1.09 \pm 0.15$ for right handers and 0.74 for one right dominant left hander.

In addition to a hemisphere laterality ratio, a regional analysis of laterality ${ }^{8}$ was performed using 3-D regions of interest (ROI'S) obtained from the average of the 10 right handed controls after each subject's functional data was transformed to the Talairach stereotaxic reference frame. Laterality was determined using $L-R$, where $L-R>0$ is left lateralized and $L-R<0$ is right lateralized, and $L$ and $R$ are mean $-\log _{\mathrm{e}} P$ for left and right homologous ROIs, respectively. A regional laterality index $(R L I)$ was computed for an $\mathrm{ROI}$ according to $R L I=L-R / L+R$ (see Table).

\section{ReSULTS}

The patient had had previous experience in an MRI scanner and was familiar with the position he had to assume within the magnet. The head coil, mirrors and screen which he had to adjust were new to him but well tolerated. The requirement for him to participate in the setup and the study appeared to make the event more novel for him, to sustain his attention and to increase his tolerance of the procedure. During the testing he was given frequent encouragement and reinforcement. At the end of the study he could not complete the final task (object naming) because of pain of one ear due to pressure on it from one of the restraining pads.

Five language studies were completed. Three of these, the two verb generation tasks and the antonym generation task yielded only noise but no significant task related activation. Both the reading words task and the letter fluency task produced activation of several areas of the brain. HLR was 1.20 for the letter fluency task and 1.04 for the reading task.

Regional laterality results for the letter fluency task using ROls generated from the average data from the 10 right handed controls on the verb generation task revealed a left dominance pattern (see Table). Of the 17 left hemisphere ROIs, 11 were left lateralized for this patient $(65 \%)$, and all 4 of the most reliably (10/10 subjects) lateralizing ROls (local maxima in areas 22 , 19(37), 6(9), and 18) were left lateralized. Both cerebellar ROIs were right lateralized which is consistent with results obtained from the right handed cohort for the generate task and with other published data on this task. ${ }^{23} 3$ of the 5 temporoparietal regions were right lateralized. (ROI numbers 13,14 , and 9). For the read words task 5 of 6 ROIs which were most reliably lateralized (i.e., at least $8 / 10$ of control subjects) were left lateralized. Of these 6, only an ROI with its local maximum in area 22 was right lateralized.

Areas showing greatest activation on the reading words task (Figure 1a) were inferior frontal gyrus, left more than right, prefrontal cortex, left premotor area, supplementary motor area, right superior temporal gyrus, left inferior occipitotemporal cortex (areas 19,37), right cerebellar hemisphere and bilateral anterior-mesial occipital cortex. This pattern of activity was quite similar to the average adult pattern except for relatively greater left frontal and anteromedial occipital activation. On the letter 
Table 1. Regional Laterality for Letter Fluency

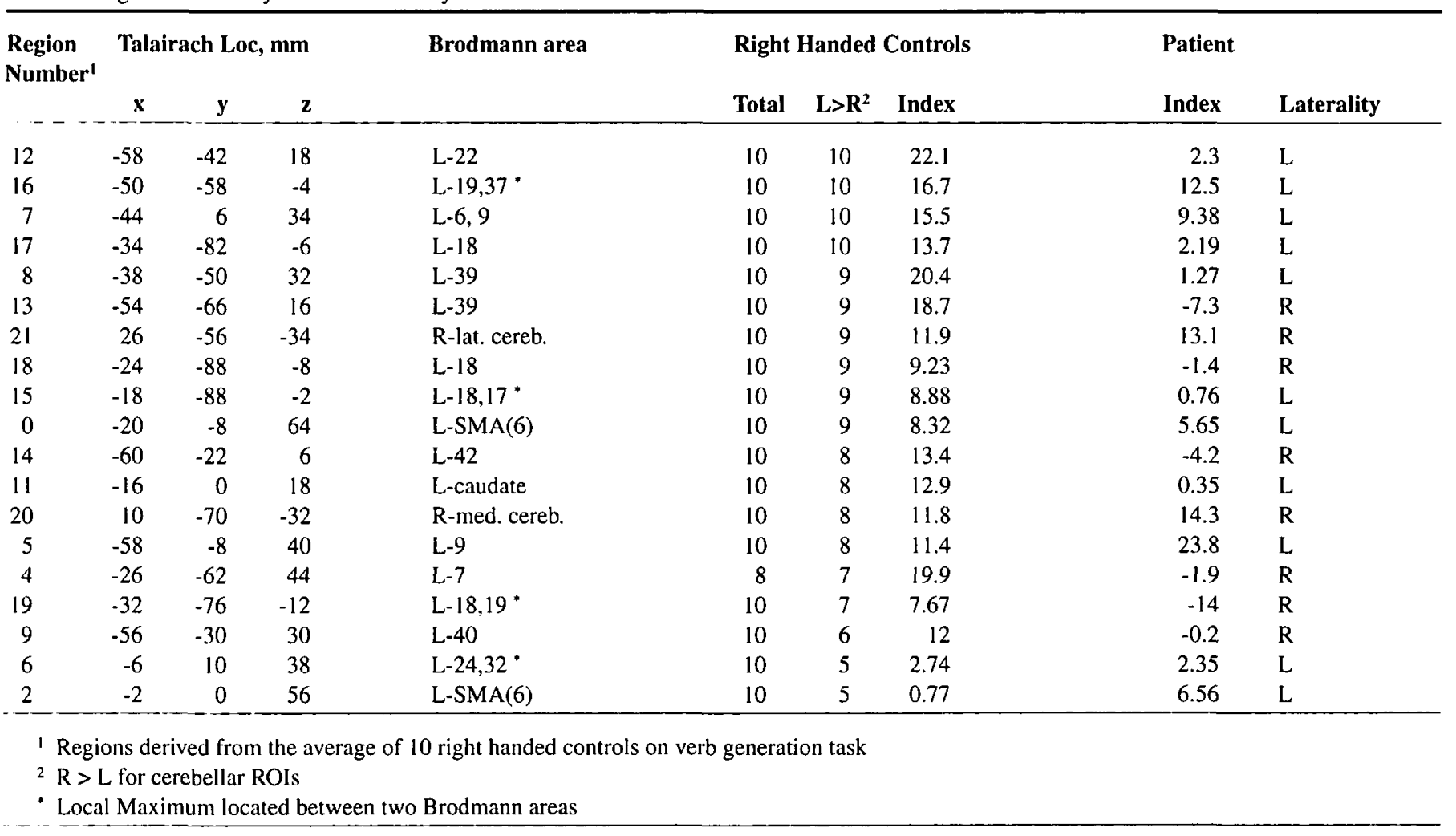

fluency task (Figure lb) left inferior frontal gyrus, left prefrontal, left premotor area, left supplementary motor area, left anterior temporal pole, left posterior superior temporal sulcus, right cerebellar hemisphere, bilateral parastriate cortex were activated. All of these foci were present in the verb generation results on normal adult righthanders ${ }^{8}$ with the exception of the left anterior temporal pole activity.

Comparison of surface rendered activity for both the reading words (Figure 2a) and letter fluency (Figure 2b) tasks demonstrates: 1) left predominance of activation for both of these tasks; 2) similarity in localization of activation foci in inferior frontal and precentral gyri; and 3) differences in distribution of activation between the two scans, with word reading showing relatively greater inferior frontal and occipitotemporal activity and letter fluency showing relatively greater parastriate activity.

\section{Discussion}

This study demonstrates the successful lateralization of language with fMRI in a child using several language tasks while imaging the whole brain. This result and other reports document both the feasibility of fMRI study in children and the hemodynamic capacity of the immature brain to respond similarly to adults. Gaillard et al. ${ }^{13}$ and Hertz-Pannier et al. ${ }^{14.15}$ have published brief reports on the use of fMRI to evaluate language in children, most of whom had epilepsy. These studies were limited to imaging of the frontal lobes but did show regional language activation. Novotny et al. ${ }^{16}$ have also studied patients with epilepsy using fMRI techniques and were successful in activating somatosensory and visual cortex with simple sensory stimuli. Casey et al., ${ }^{12}$ using a working memory paradigm, have been able to show frontal activation in normal children similar to that seen in adults.

The patient in this report might be considered a suboptimal candidate for fMRI investigation with impaired verbal function and attentional difficulty. These potential limitations were successfully addressed by using a range of tasks adapted to his abiltities. Multiple language paradigms were used in order to increase the likelihood of successfully revealing language cortex and to show common areas of language activation across the tasks.

The verb generation task has been found to produce lateralized cortical activation in adults. ${ }^{8,24,25}$ Unfortunately, despite using two different stimulus rates, in our patient no reliable activation was seen using this task. Some possible explanations for this failure include the patient's impaired verbal ability, lack of effort, and inappropriateness of the task for his level of developmental maturation. The letter fluency task, despite a lack of $a$ priori fMRI study in normals was used in this case because it was presumed to be a less demanding test of fluency. Theoretically, there are fewer linguistic constraints, i.e., semantic and syntactic, imposed in the selection of a lexical item compared with the verb generation task. In the practice session the patient's performance was more consistent for the letter fluency task compared with the verb generation task. The letter fluency task produced activation of areas similar to the adult pattern for the verb generation task with an additional focus of activity in the left temporal pole. Given that this finding was not repeated in the read task and that at present there exists no normative data on this task for reference, one may speculate that, if not a spurious or artifactual finding, it may be related to the patient's left temporal lobe pathology. Alternatively, it may represent idiosyncratic language processing in this patient or a normal site of 

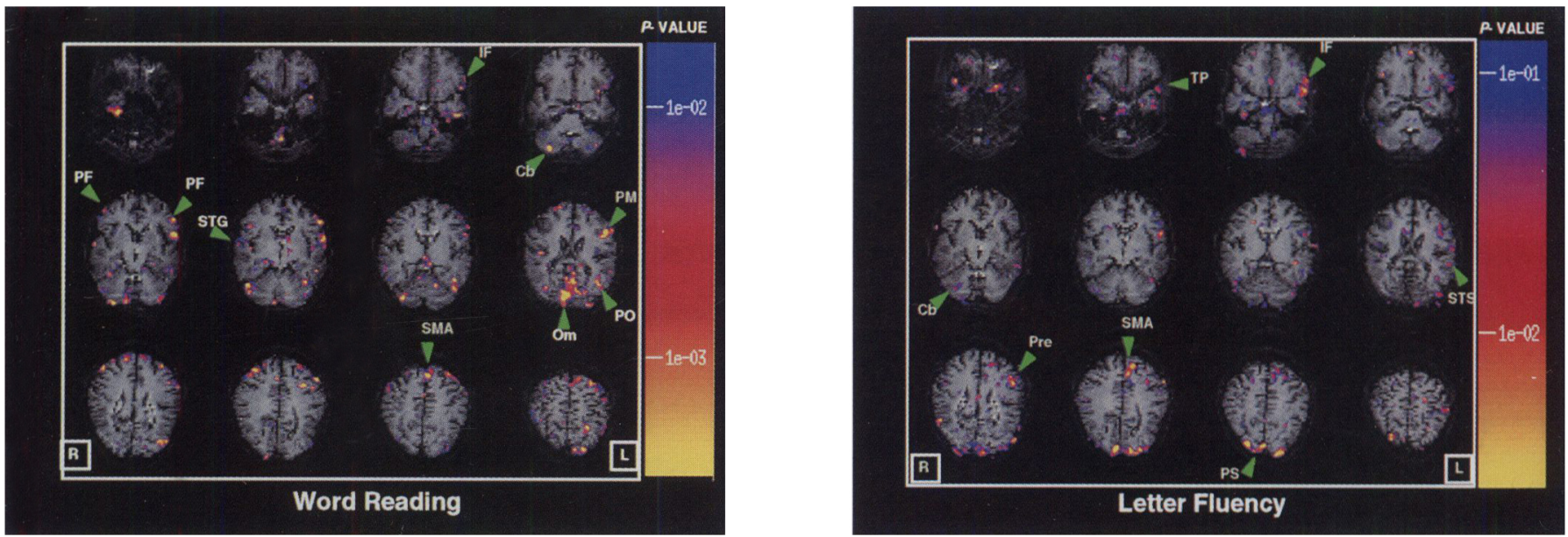

Figure 1. Statistical maps (KS) of language task vs. baseline (fixation) in actual oblique axial slice orientation overlaid on high resolution (I.5mm inplane) image. a) Reading words vs. fixation, b) Letter fluency vs. fixation; Key: $C b=$ cerebellum, IF=inferior frontal, Om=medial occipital, PS $=$ Parastriate, $P F /$ Pre =prefrontal, $P M=$ premotor, $P O=$ parieto-occipital, SMA=supplementary motor area, STS=Superior Temporal Sulcus, $S T G=$ Superior Temporal Gyrus, $T P=$ temporal pole.
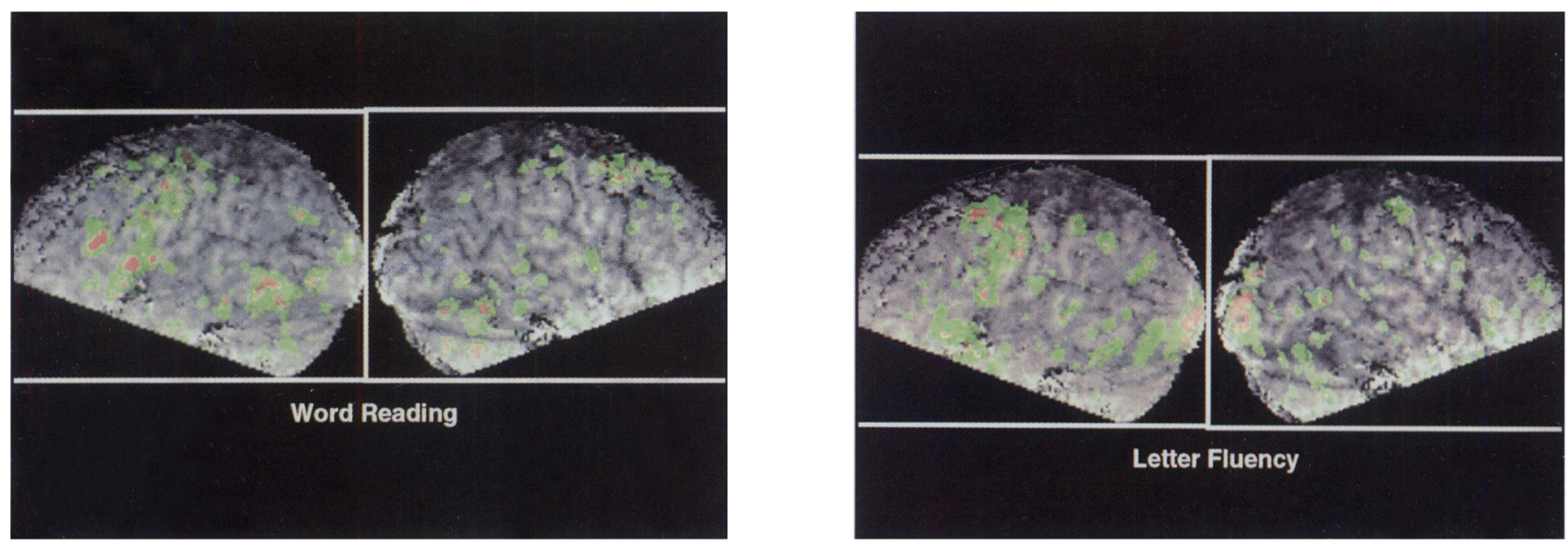

Figure 2. Surface rendered activity (lateral) for left and right hemispheres for: a) Reading words vs. fixation $(p<0.01), b)$ Letter fluency vs. fixation $(p<0.1)($ see Text).

activation related to differential processing between the letter fluency and verb generation tasks employed in this study.

The antonym generation paradigm was used to test semantic knowledge. The patient performed this well during practice, but it did not produce significant activation during imaging. One possible explanation for the lack of significant activity could be overlearned automatic responses to the list of words presented. On the other hand, there is little evidence in this study to support a significant item-specific practice effect causing a substantial reduction in activation. The read words task, which included a high proportion of previously presented items, produced a pattern of activity which was qualitatively similar to adults on their first exposure to the exposure to the stimulus items. If anything, the patient showed more activity than adults typically do on this task despite the repetition of items from the practice session.

A different pattern of activity in extrastriate cortex between the two tasks is difficult to explain without more fMRI data for the letter fluency task in normal controls. The greater occipitotemporal activity observed for the read words task compared with letter fluency is consistent with strong and lateralized area 37 and 19 activity for word reading in adults. ${ }^{8}$ These areas have been associated with object recognition in several studies of primates and humans ${ }^{26-29}$ using different imaging modalities. Perception of a visual word as a familiar object or, alternatively, the high imageability ${ }^{30}$ of the concrete nouns used in this task may explain this activation. By comparison, the letter fluency task involves a simpler visual stimulus (a letter) which may be insufficient to activate ventral temporal and occipital cortex, and generated words will have variable imageability. The bilateral parastriate activity in this task may be related to prelexical orthographic (letter level) processing needed to complete the brief "stem". The greater anteromedial activation for word reading was also found by Petersen, et al. for words and pseudowords but not consonant strings. ${ }^{31}$ This may reflect greater orthographic or lexical processing on the read words task compared with a single letter presentation.

The strong frontal activity on the reading task compared to adult controls, which included lateralized and midline (SMA) 
activity, may be explained by his poor verbal and lexical skills for his age as indicated by neuropsychological assessment. Thus, greater difficulty would engender greater linguistic and metalinguistic (attentional) demands resulting in greater activity of lateralized and midline frontal structures, respectively.

Gaillard et al. ${ }^{13}$ and Hertz-Pannier et al. ${ }^{14,15}$ also used a word generation paradigm but some of their subjects did not show language activation or lateralization. If activation is not seen and the patient is reasonably cooperative, then an inappropriate task for that individual may have been used. In the present case several paradigms were studied but only two of these produced activation. Since the analyzed results are not immediately available with fMRI studies, it may be necessary to test a variety of paradigms converging on fluency and semantics during the functional study before concluding that language localization and lateralization is not possible.

Left hemisphere dominance for language was strongly suggested by the fMRI results for the patient described in this report. Both reading words and letter fluency were shown to be left lateralized by HLR within the range of the right handed controls. The HLR of 1.20 obtained for letter fluency would be at the low end for verb generation; however, it is not the same task and probably underestimates the degree of laterality indicated by the verb generation task, since the linguistic constraints of this task are fewer than the verb generation task. Left hemisphere laterality is further supported by regional laterality results considering only the most reliable ROIs for each task. Interestingly, 3 of the 5 temporoparietal regions were right lateralized, and of the 6 most reliably lateralizing ROIs on the read task, only an ROI in area 22 of the temporal lobe was right lateralized. Taken together, the tendency in this patient for temporoparietal language regions to lateralize to the right or weakly to the left may reflect a shift of language function to the right hemisphere due to a longstanding and probably developmental abnormality of the left temporal lobe. Neural plasticity is greatest in immature brains especially younger than 7 years when most language function is recovered after left hemispherectomy. ${ }^{32}$ This "right shift" would be expected to lower the hemispheric determination of laterality (HLR). This effect more than task differences between letter fluency and verb generation may be the more significant mechanism explaining the weak left dominance.

The left inferior frontal area (areas 44, 45, 46) shows strong activation and lateralization with many language tasks. 4.5 .9 .33 .34 The supplementary motor area and premotor area are also often activated in language tasks, especially if there is a covert or overt response which is not present in the control condition. ${ }^{35}$ Posterior language areas are less well activated by the visual tasks employed and generally do not produce reliable lateralization as do the lateral frontal regions. ${ }^{8}$ More reliable activation of superior temporal and temporo-parietal language cortex is produced with auditory language tasks and visual tasks requiring phonological processing. ${ }^{24,36.37}$

At present, our strategy has been to target clinically relevant regions of cortex by using a set of language tasks which tend to activate eloquent cortex in the same general region. As we begin to better characterize normal variability as well as distinctly abnormal patterns of activity and are able to correlate these patterns with behavioral abnormalities, fMRI will become an important diagnostic tool. Developmental language disorders such as dyslexia may be may be recognized by a characteristic pattern or a limited set of patterns of activity on particular language paradigms. These abnormal patterns will reflect the primary neural/cognitive defect as well as compensatory mechanisms, especially if developmental in etiology.

Practicing of the tasks and procedures with the child was essential. If these are presented in a noncompetitive and reassuring manner, some patient/parent anxiety may be relieved. An important objective of this preliminary visit is to modify and adjust the tasks to the patients ability and to bolster his confidence in his ability to complete the study. Prior introduction to the MRI scanner also serves to alleviate anxiety and prepare the patient for the many novel aspects of fMRI. At the time of study, the visual stimuli and a trial of the task can be presented as a final rehearsal. During the fMRI session frequent communication, reassurance and encouragement seems to be helpful.

The major source of artifact in fMRI is motion artifact. It is expected that children, especially those with cognitive impairments, will move more than adults during testing, but this is conjecture. We applied several strategies to reduce head movement in this study. First, the patient was frequently reminded to hold still. Secondly, the patient's head was immobilized by physical restraints within the head coil. Unfortunately, this may result in pressure points becoming painful after a long study as was seen in our patient. Attention to a comfortable but confining head restraint can improve the chances for a successful study. Finally, post-processing motion correction algorithms can correct for relatively slow bulk movements of the brain which occur during image acquisition. ${ }^{19,20}$

FMRI has several advantages for the localization of critical brain function in children. It is noninvasive and can be repeated several times. A variety of cortical functions can be evaluated at one session. Functional and structural data are acquired at the same time and are easily coregistered. This may have important implications in the planning and execution of cortical resections and other neurosurgical procedures. More than any other currently available technique, fMRI should also be useful in the study of development and plasticity. As described in this report, by using hemispheric and regional approaches to laterality, it may possible to infer endogenous hemisphere dominance as well as neural reorganization which occurs as a consequence of injury. During childhood the brain undergoes major changes in anatomy and physiology as well as in language and other cognitive abilities which could influence its response to functional activation. ${ }^{12.38 .39}$ In the immature brain certain higher level linguistic operations such as verb generation may not be sufficiently organized or anatomically localized to have discrete hemodynamic correlates. More must be known about the characteristics of fMRI activation in the developing brain in order to determine the optimal tasks for localization of language and other cognitive functions. The present report demonstrates that cognitive paradigms useful in adults may not always be directly applicable to young children. However, by modifying timing parameters and, when necessary, simplifying tasks to accommodate to a subject's ability level, one may successfully image even quite young children as reported in this study.

\section{ACKNOWLEDGEMENTS}

The authors thank David B. FitzGerald for his help with references and proofreading. 


\section{REFERENCES}

1. Wada J and Rasmussen, $\mathrm{T}$. Intracarotid injection of sodium amytal for the lateralization of cerebral spech dominance. J Neurosurg $1960 ; 17: 266-282$.

2. Pardo JV and Fox, PT. Preoperative assessment of the cerebral hemisphere dominance for language with CBF PET. Human Brain Mapping 1993; 1: 57-68.

3. Kwong KK, Belliveau, JW, Chesler, DA, et al. Dynamic magnetic resonance imaging of human brain activity during primary sensory stimulation. Proc Natl Acad Sci U S A 1992; 89: 56755679.

4. Benson RR, Kwong, KK, Buchbinder, BR, et al. Noninvasive evaluation of language dominance using functional MRI. In: Proceedings of the Society of Magnetic Resonance 2nd Annual meeting, San Francisco 1994: 684.

5. Binder JR, Rao, SM, Hammeke, TA, et al. Lateralized human brain language systems demonstrated by task subtraction functional magnetic resonance imaging. Arch Neurol 1995; 52: 593-601.

6. Desmond JE, Sum, JM, Wagner, AD, et al. Functional MRI measurement of language lateralization in Wada-tested patients. Brain 1995; 118:1411-1419.

7. McCarthy G, Blamire, AM, Rothman, DL, et al. Echo-planar magnetic resonance imaging studies of frontal cortex activation during word generation in humans. Proc Natl Acad Sci U S A 1993; 90: $4952-4956$.

8. Benson RR, Belliveau, JW, Kwong, KK, et al. Preoperative mapping of language cortex with functional MRI. In: Proceedings of the Ist International Conference on Functional Mapping of the Human Brain, Paris, 1995: 351.

9. Shaywitz BA, Shaywitz, SE, Pugh, KR, et al. Sex differences in the functional organization of the brain for language. Nature 1995; 373: 607-609.

10. Jones-Gotman M. Presurgical psychological assessment in children: special tests. J Epilepsy 1990; 3 Suppl.: 93-102.

II. Jones-Gotman M, Barr, WB, Dodrill, CB, et al. Controversies concerning the use of intraarterial amobarbital procedures. In: J. J. Engel, ed. Surgical Treatment of the Epilepsies. New York: Raven Press, 1993; 445-449.

12. Casey BJ, Cohen, JD, Jessard, P, et al. Activation of prefrontal cortex in children during a non-spatial working memory task with functional MRI. Human Brain Mapping Suppl 1995; 1: 330.

13. Gaillard WD, Hertz-Pannier, L, Mott, S, et al. Identification of cortical language areas using $1.5 \mathrm{~T}$ functional magnetic resonance imaging in children with epilepsy. Ann Neurol 1994; 36: 504.

14. Hertz-Pannier L, Gaillard, WD, Mott, S, et al. Pre-operative assessment of language lateralization by FMRI in children with complex partial seizures: preliminary study. In: Proceedings of the Society of Magnetic Resonance 2nd Annual Meeting, San Francisco 1994: 326.

15. Hertz-Pannier L, Gaillard, WD, Mott, S, et al. Functional MRI of language tasks: frontal diffuse activation patterns in children. Human Brain Mapping Suppl. 1995; 1: 231.

16. Novotny EJJ, Masuoka, LK, Anderson, AW and et.al. Functional magnetic resonance imaging in pediatric epilepsy. Epilepsia 1994; 35 Suppl 8: 36.

17. Logan WJ, Benson, RR, Cosgrove, GR, et al. Functional MRI (fMRI) localization of language in children. Can J Neurol Sci 1995; 22 Suppl 1: 24.

18. Holmes $\mathbf{G}$ and Frosch, $M$. Case records of the Massachusetts General Hospital. N Engl J Med 1996; 334: 586-592.

19. Jiang A, Kennedy, DN, Baker, JR, et al. Motion detection and correction in functional MR imaging. Human Brain Mapping (in press).
20. Woods RP, Cherry, SR and Mazziotta, JC. Rapid automated algorithim for aligning and reslicing PET images. J Comput Assist Tomogr 1992; 16: 620-633.

21. Breiter HC, Rauch SL, Kwong KK et al. Functional magnetic resonance imaging of symptom provocation in obsessive compulsive disorder. Arch Gen Psychiatr 1996:In Press.

22. Robb RA and Parillot, C. Interactive display and analysis of $3 D$ medical images. IEEE Trans Med Imag 1989:8:217-226.

23. Petersen SE and Fiez, JA. The processing of single words studied with positron emission tomography. Ann Rev Neurosci 1993; 509-529.

24. Petersen SE, Fox, PT, Posner, MI, et al. Positron emission tomographic studies of the cortical anatomy of single-word processing. Nature 1988; 331: 585-589.

25. Wise R, Chollet, F, Hadar, U, et al. Distribution of cortical neural networks involved in word comprehension and word retrieval. Brain 1991; 114: 1803-1817.

26. Corbetta M, Miezin, FM, Dobmeyer, S, et al. Selective and divided attention during visual discriminations of shape, color, and speed: functional anatomy by positron emission tomography. J Neurosci 1991; 11: 2383-2402.

27. Allison T, Ginter, H, McCarthy, G, et al. Face recognition in extrastriate cortex. J Neurophysiol 1994; 71: 821-825.

28. Haxby JV, Grady, CL, Horowitz, B, et al. Dissociation of object and spatial visual processing pathways in human extrastriate cortex. Proc Natl Acad Sci 1991; 88: 1621-1625.

29. Sergent J, Ohta, S and Macdonald, B. Functional neuroanatomy of face and object processing. A positron emission tomography study. Brain 1992; 115: 15-36.

30. Martin N and Saffran, E. A computational account of deep dysphasia: evidence from a single case study. Brain-Lang. 1992; 43: 240-74.

31. Petersen SE, Fox, PT, Snyder, AZ and Raichle, ME. Activation of extrastriate and frontal cortical areas by visual words and wordlike stimuli. Science 1990; 24: 1041-1044.

32. Woods BT and Teuber, HL. Changing patterns of childhood aphasia. Ann. Neurol. 1978; 3: 273-80.

33. Benson RR, Kwong, KK, Belliveau, JW, et al. Magnetic resonance imaging studies of visual word recognition: words versus false font strings. In: Proceedings of the 23rd Annual Meeting of the Society for Neuroscience, Washington, DC: 1994; 740.1.

34. Zatorre R, Evans, A, Meyer, E and Gjedde, A. Lateralization of phonetic and pitch discrimination in speech processing. Science 1992; 256: 846-9.

35. Stephan KM FG Passingham RE, Silbersweig D, CeballosBaumann AO, Frith CD, Frackowiak RS. Functional anatomy of the mental representation of upper extremity movements in healthy subjects. J of Neurophysiol 1995; 73: 373-386.

36. Dehaene-Lambert G and Dehaene, S. Speech and cerebral correlates of syllable discrimination in infants. Nature 1994; 370: 292-5.

37. Benson RR, Buchbinder, BR, Jiang, $\mathrm{H}$, et al. Comparison of $\mathrm{AMRI}$ with electrocortical stimulation language mapping. In: Proceedings of the Society for Neuroscience 25th Annual Meeting, San Diego: 1995; 116.8 .

38. Chugani HT, Phelps, ME and Maziotta, JC. Positron emission tomography study of human functional development. Ann Neurol 1987; 22: 487-497.

39. Huttenlocher PR, De Courten, C, Gareu, LJ and Van Der Loos, H. Synaptogenesis in human visual cortex - evidence for synapse elimination during normal development. Neurosci Lett 1982; 33: 247-252. 